\title{
KESERAKAHAN CELENG: KETAMAKAN DALAM KESADARAN MORAL
}

\author{
Dionius Bismoko Mahamboro
}

\begin{abstract}
:
In the Javanese culture, the wild Boar is a symbol of greed or avarice. In this article, boar as a symbol is seen as a language for expressing moral consciousness. Moral consciousness of the dangers of avarice has been started since the beginning of the Christian era and passed on to us through present time in the form of the Doctrine of the seven principal or deadly Sins. So here is presented the evolution of this consciousness perceiving greed as a moral problem, especially in the Biblical and Patristic tradition. Given that the use of wild Boar as a symbol of greed is associated with sociological background, the article shows also the reception of avarice as one of the seven deadly sins in the sociological science. These two different perspectives of how one speaks about avarice as a moral problem are useful to develop a more comprehensive understandings on avarice and a contextual language, expressing it as a moral issue that should never be overlooked in Indonesia.
\end{abstract}

\section{Kata-kata Kunci:}

keutamaan, watak buruk, ketamakan, tujuh dosa pokok.

\section{PENDAHULUAN}

\subsection{Latar Belakang Masalah}

Di seputar Reformasi Indonesia, perupa Djoko Pekik menghasilkan tiga buah karya lukis yang menampilkan obyek visual utama binatang celeng. Celeng telu - istilah si perupa untuk ketiga karyanya - hendak mengisahkan riwayat hidup yang tidak elok dan tragis dari si celeng (babi hutan). Semasa hidup ia amat rakus dan tidak pernah kenyang (Susu Raja Celeng, 1996). Ini sesuai dengan asosiasi negatif kebanyakan orang terhadap celeng: perusak areal pertanian, hama pengganggu, pencuri hasil bumi yang sedang dinanti panennya oleh petani. Namun akhirnya si celeng rakus tertangkap sehingga semua orang bergembira (Indonesia 1998, Berburu Celeng, 1998). Akhirnya ia matibangkainya membusuk dan jadi santapan gagakgagak - dalam kesendirian, di alam yang tandus (Tanpa Bunga dan Telegram Duka,1999).
Lantas dimulailah tafsir terhadap celeng. Pada lukisan trilogi celeng, para pengamat seni menangkap fase-fase runtuhnya Orde Baru, sekaligus menafsirkan celeng sebagai simbolisasinya. ${ }^{1}$ Namun bagi Sindhunata, si celeng rakus tidak hanya menyimbolkan penguasa yang serakah dan kroni-kroninya, melainkan semua orang yang dirasuki oleh nafsu keserakahan. Dalam novel Tak Enteni Keplokmu: Tanpa Bunga dan Telegram Duka Sindhunata menulis, “... celeng itu juga simbol kejahatan, kekuasaan kegelapan, yang tak mudah ditandingi bahkan dengan kebaikan dan kuasa terang."2 Dalam lukisan Berburu Celeng yang lahir tak lama setelah kejatuhan Orde Baru digambarkan sukacita atas tertangkapnya si celeng rakus. Namun latar belakang gelap juga dihadirkan oleh Pekik sebagai tanda ketidakpastian akan masa depan. Kendati si celeng sudah tertangkap, belum tentu keadaan segera berubah menjadi lebih baik. Seandainya si celeng rakus menyimbolkan rezim pemerintahan yang korup dan menyedot segala sesuatu untuk kekayaan dirinya sendiri, maka 
terbuktilah kini "ramalan" Pekik: lima belas tahun sudah euforia akan berakhirnya Orde Baru berlalu, namun justru korupsi makin marak dan kehidupan bernegara semakin rusak. ${ }^{3}$ Interpretasi terhadap realitas yang disimbolkan oleh celeng mengalami pergeseran. Awalnya rezim penguasa yang rakus dan kroni-kroninya dipandang sebagai hama perusak kehidupan bernegara yang harus dibasmi. Namun ternyata "musuh" yang sesungguhnya adalah "roh jahat ketamakan" yang bisa merasuki semua orang tanpa pandang bulu.

Saat Djoko Pekik mengangkat celeng sebagai simbol ketamakan, dan ketika Sindhunata memaknai "roh celeng yang saat ini bergentayangan" sebagai bahaya serius yang mengancam hidup bersama masyarakat Indonesia saat ini, terbuka ruang untuk membicarakan ketamakan yang dipandang sebagai kekuatan impersonal yang merusak tata kehidupan bersama manusia. Dalam bahasa teologi, kekuatan ini disebut sebagai dosa. Dalam tradisi moral teologi, ketamakan ini bahkan termasuk salah satu dari ketujuh dosa pokok. ${ }^{4}$

\subsection{Rumusan Masalah}

Berbagai fenomena ketamakan yang ada dalam praksis hidup bermasyarakat mengusik penulis untuk membuat meneliti hal ini. Penelitian ini berfokus pada tiga permalalahan pokok. Pertama, bagaimana tradisi blibis menjelaskan fenomena ketamakan manusia? Kedua, dari perspektif ajaran moral mengenai tujuh dosa pokok, bagaimana ketamakan bisa dijelaskan? Ketiga, bagaimana ketamakan manusia dijelaskan secara sosiologis?

\subsection{Tujuan Penulisan}

Dalam tulisan ini hendak dibandingkan, bagaimana ketamakan dibicarakan dalam bahasa biblis, dalam tradisi moral, khususnya dalam kerangka asal muasal ajaran tujuh dosa pokok, dan dalam bahasa sosiologis. Ketamakan sebagai hasrat berlebihan terhadap barang dan kemakmuran, termasuk keinginan untuk memiliki apa yang menjadi milik orang lain, adalah perilaku yang selalu ada sepanjang zaman.

Tujuan utama dari penelitian analitis komparatif kajian biblis, moral dan sosial ini adalah untuk menemukan signifikansi diskursus ketamakan dalam ranah teologi moral di
Indonesia. Tujuan lain dari penelitian ini adalah untuk menjelaskan ketamakan yang terjadi di dalam masyarakat berdasarkan kajian yang lebih komprehensif.

\subsection{MetodePenulisan}

Penelitian ini menggunakan metode analisis diskpriptif dari perspektif teologi biblis, ajaran moral mengenai tujuah dosa asal, dan kajian sosiologis untuk memahami dan menjelaskan persoalan ketamakan. Lanasan teori dari perspektif teologi biblis dan moral serta kajian sosiologis akan dielaborasi secara langsung untuk mengalalisis persoalan ketamakan.

\section{KETAMAKAN DALAM TRADISI BIBLIS}

Karakter negatif yang menonjol dari celeng adalah sifat rakusnya. Ia sepertinya tak pernah merasa puas akan apa yang telah dimakan atau diperolehnya. Keinginan untuk menambah kepemilikan ini lantas menjadi ciri utama ketamakan yang diwakili oleh celeng dalam lukisan Pekik. Menambah jumlah hak milik tentunya tidak pernah dipandang salah secara moral. Akan tetapi kecenderungan manusiawi untuk menambah jumlah hak milik supaya semakin banyak ini berpotensi melahirkan kejahatan. Ketika Yesus menceritakan perumpamaan tentang orang kaya yang bodoh (Luk 12:13-21), Ia mengangkat perbincangan mengenai hak milik, sekaligus mengenai bahaya keinginan memiliki semakin banyak lagi. Yesus didatangi seseorang yang meminta bantuannya untuk mendapatkan jatah warisan orangtua dari saudaranya yang lebih tua. ${ }^{5}$ Dihadapkan dengan kasus pembagian harta seperti ini, Yesus berkata-kata dengan keras, "Berjaga-jagalah dan waspadalah terhadap segala ketamakan!" (ay. 15). Ketamakan (Yun. pleonexia) ini lantas dijelaskan Yesus dengan perumpamaan mengenai orang kaya yang ingin menimbun lebih banyak hasil panenan ladangnya (ay. 16-21). Peringatan Yesus ini mengindikasikan adanya daya destruktif pada keinginan yang berlebihan dalam menambah jumlah kepemilikan.

Istilah pleonexia ini hanya muncul dua kali dalam Injil: dalam perikop Lukas di atas dan di Mrk 7:22, di mana ketamakan muncul dalam daftar watak-watak buruk ${ }^{6}$ (list of vices, Lasterkatalog) yang keluar dari hati. Ketamakan 
memang bukan kosakata yang sering dipakai di Injil. Ia termasuk dalam perbendaharaan kata yang sering digunakan Paulus, khususnya dalam pengajaran moral mengenai daftar keutamaan dan watak-watak buruk (virtues and vices). Pleonexia berarti keinginan untuk memiliki (barang atau previlese) lebih daripada orang lain. Ia juga mencakup keinginan untuk menguasai.

Yesus mendorong kewaspadaan terhadap ketamakan karena keselamatan manusia tidak tergantung dari kelimpahan kekayaannya. Dengan perumpamaan orang kaya di Injil Lukas, Yesus menunjukkan bahaya dari keinginan untuk mengumpulkan lebih banyak lagi. Di balik ketamakan tersembunyi ketakutan yang mendorong manusia untuk memiliki lebih banyak dari orang lain, bahkan lebih dari apa yang sebenarnya dibutuhkan. Di balik ketamakan ini terdapat sesat pikir, bahwa memiliki (to have) lebih penting daripada berada (to be), bahwa hidup manusia ditentukan oleh kepemilikannya. ${ }^{7}$ Jika seseorang mencari lebih banyak lagi penghasilan karena didorong oleh ketakutan akan kekurangan, maka ia menjadikan uang sebagai tujuan hidupnya. Orientasinya adalah mengumpulkan kekayaan.

Dengan perumpamaan ini, Yesus memberi tanda bahaya pada segala bentuk kekayaan material. Peringatan ini sesuai dengan kritik Yesus terhadap kekayaan atau kepemilikan. "Tak seorangpun hamba bisa mengabdi dua tuan ... kalian tidak bisa mengabdi Allah dan Mamon." (Luk 16:13 par). ${ }^{8}$ Kata semitik Mamon, yang berarti kepemilikan/barang yang dimiliki/harta benda jelas digunakan dalam arti negatif. Bahwa jemaat Kristen awal menyerap kata asing mamon tanpa terjemahan, tampaknya menjadi dasar, bahwa orang memandang ketamakan - keinginan untuk mengumpulkan harta benda lebih banyak - mempunyai kualitas seburuk penyembahan berhala. ${ }^{9}$ Harta benda atau kekayaan memiliki karakter jahat karena ia membelenggu dan menghambat manusia mengalami Kerajaan Allah, inti pewartaan Yesus.

Asosiasi keserakahan dengan penyembahan ini muncul juga dalam Kol 3:5, "keserakahan sama dengan penyembahan berhala". ${ }^{10}$ Konsep penyembahan berhala diwarnai oleh pengalaman umat Israel dalam Perjanjian Lama, di mana eksklusivitas hak Allah akan sembah bakti dan kepercayaan manusia dilanggar oleh manusia sendiri. Ini adalah pelanggaran manusia yang paling berat di mata Allah. Sementara konsep keserakahan di sini bisa ditelusuri dari setting sosial cara hidup jemaat Kristen di abad-abad pertama. Kis 4:32-37 memberi kesaksian mengenai karakter jemaat perdana dalam hal kegiatan karitatif yang didukung oleh kebiasaan berkumpul, berdoa dan makan bersama. Ungkapan lahiriah ini dikembangkan menjadi praksis yang bermuara pada identitas bersama, bahwa orang-orang Kristen adalah satu saudara/keluarga baru yang saling menanggung beban satu sama lain. Dalam situasi ini tentu saja keserakahan menjadi ancaman terhadap keberlangsungan jemaat Kristen sebagai sebuah gerakan. Tampaknya bukan suatu kebetulan, jika kisah mengenai cara hidup jemaat perdana segera disusul oleh kisah Ananias dan Safira yang diangkat sebagai contoh pribadi-pribadi serakah (Kis 5:1-11). Maka keserakahan tidak hanya berarti "keinginan untuk memiliki lebih banyak (barang material)", namun juga sikap tidak mau berbagi atau kikir. Dalam Ef 5:5 terdapat formula yang paralel dengan Kol 3:5, yakni: "orang serakah (pleonektes), artinya penyembah berhala" (bdk. 1Kor 5:10f; 6:10).

Dalam surat-surat Paulus, pleonexia terdapat dalam daftar watak-watak buruk atau kejahatan (lih. Rm 1:29; Ef 5:3; Kol 3:5) yang harus dihindari - istilah Paulus: "ditanggalkan" - oleh orang Kristen. Untuk melawan watakwatak buruk ini Paulus mendorong jemaat untuk mengembangkan ("mengenakan") keutamaan, yang daftarnya dimunculkan sebagai tandingan watak-watak buruk (lih. Ef 4:24; Kol 3:12). Daftar watak buruk dan keutamaan ini memainkan peran penting dalam pewartaan Paulus dalam rangka membangun moral jemaat. Kualitas moral inilah yang menentukan dan membedakan eksistensi jemaat Kristen dengan masyarakat umum. ${ }^{11}$ Bagi Paulus, menjadi Kristen berarti menjadi manusia baru, berarti meninggalkan kebiasaan-kebiasan (buruk) lama dan membangun kebiasaan-kebiasaan baru. Bahwa ketamakan termasuk dalam daftar pengajaran moral Paulus untuk jemaat, mengindikasikan karakter komunal dari watak buruk ini. Ia bukan semata-mata persoalan individual.

Keinginan untuk mendapatkan sesuatu lebih banyak lagi, khususnya uang, disebut Paulus sebagai bahaya bagi para pemimpin jemaat. Ia mensinyalir adanya orang-orang mengeksploitasi jemaat Kristen untuk memperoleh uang demi keuntungan mereka sendiri. Mereka menggunakan ibadat sebagai kesempatan me- 
ngumpulkan uang. Oleh karena itu ia perlu memberi nasihat (lih. 1Tim 6:2b-10) yang ditutup dengan sebuah pepatah yang tampaknya cukup dikenal: "Cinta akan uang adalah akar dari segala kejahatan." (ay. 10). Gagasan ketamakan di sini muncul dengan istilah filargyria (terjemahan harafiah: cinta akan perak); menunjuk secara eksklusif nafsu dan keterikatan terhadap uang. Keinginan untuk menjadi lebih kaya, memiliki uang lebih banyak dikontraskan dengan sifat kecukupan (autarkeia, ay. 6) yang berakar pada iman dan penyerahan total pada penyelenggaraan Allah. ${ }^{12}$ Disposisi ini menjadi dasar logika dalam penyelenggaraan kebutuhan hidup serta distribusi kesejahteraan. Salah satu pokok iman Kristen adalah kepercayaan akan Allah, sang pencipta. Konsekuensi dari credo ini adalah cara pandang spiritual terhadap realitas material. Kepemilikan materi secara umum dipandang berbahaya baik secara spiritual maupun moral. Dalam cara pandang ini orang Kristen lantas merespon situasi konkrit distribusi kesejahteraan yang tidak merata. Kepemilikan pribadi mudah menyebabkan dinding pemisah antara orang kaya dan miskin, sementara dalam cinta kasih Kristiani diakui bahwa orang kaya dan miskin adalah saudara. Paulus mengajak orang Kristen untuk merasa cukup dengan hal-hal yang perlu saja. Keinginan untuk mendapatkan uang lebih banyak akan membawa seseorang ke dalam godaan-godaan untuk melakukan hal-hal yang buruk, bahkan jahat.

Pada dua abad pertama, jemaat-jemaat Kristen menggunakan medium yang lazim pada zamannya - daftar keutamaan dan watak-watak buruk adalah salah satu di antaranya - untuk mengungkapkan pendirian moralitasnya. ${ }^{13}$ Materi katalog keutamaan dan watak buruk di atas tentu saja bukan temuan Gereja Kristen, melainkan pandangan moral yang datang dari aneka sumber, baik kesusasteraan kebijaksanaan Yahudi maupun filsafat Yunani. Maka wajar jika keutamaan atau watak buruk dalam surat-surat Paulus muncul begitu saja, tanpa referensi kristologis. Mengapa ini termasuk keutamaan, mengapa itu termasuk watak buruk, sudah terbukti dengan sendirinya. Bahwa orang Kristen dalam aspekaspek kehidupan tertentu, misalnya mengenai harta dan kepemilikan, mempunyai pandangan yang berbeda dari masyarakat pada umumnya, merupakan respon iman Gereja terhadap realitas konkrit, kendati saat itu belum ada ajaran moral sosial yang sistematis.

\section{KETAMAKAN BERDASARKAN AJARAN MORAL TENTANG TUJUH DOSA POKOK}

Di zaman para bapa Gereja, keserakahan - lazim disebut sebagai filargyria - terhitung dalam daftar watak-watak buruk pokok (lat. vitia principalia) yang akhirnya berkembang menjadi ajaran tujuh dosa pokok (seven principal sins). Katekismus Gereja Katolik (KGK) memberi petunjuk, bahwa ajaran mengenai tujuh dosa pokok dalam tradisi kristiani banyak dihubungkan dengan nama St. Yohanes Kassianus $( \pm 360-435)$ dan St. Gregorius Agung $( \pm 540$ 604). Dalam KGK, digunakan dua istilah secara bergantian, yakni kebiasaan-kebiasaan buruk (seven principal vices) dan dosa-dosa pokok, sebagaimana Gregorius juga menggunakannya demikian. Pada era sebelumnya, zaman bapabapa padang gurun pada abad ke-4, telah berkembang ajaran mengenai watak-watak buruk pokok ini (principal vices) yang umumnya berjumlah delapan. Evagrius dari Pontus $( \pm 345$ 399), bapa padang gurun dari Mesir, umum dikenal sebagai pengembang sistem "delapan pikiran jahat (logismoi)" sebagai panduan untuk hidup rohani para rahib eremit Mesir pada abad ke-4. Yohanes Kassianus lalu memodifikasi sistem ini menjadi ,delapan kebiasaan buruk utama" (vitia principalia) untuk para rahib senobit (di gereja Latin/Barat) pada awal abad ke-5. Kemudian Gregorius membawa konsep itu keluar dari lingkup monastik. Sebagai seorang gembala (uskup) ia menggunakan ajaran para rahib itu sebagai pedoman kehidupan umat awam.

\subsection{Evagrius dari Pontus}

Sebagai "formator" para rahib eremit, Evagrius menulis secara sistematis prinsipprinsip dan panduan untuk hidup monastik. Bagi Evagrius, isi kehidupan asketik (yang ia sebut praktike) adalah memberi perhatian secara khusus pada pikiran-pikiran (logismoi $)^{14}$ yang seringkali menghantar rahib kepada kedosaan.Oleh karenanya pikiran-pikiran ini perlu dianalisis dan diatur sedemikian rupa baik melalui dispilin fisik maupun rohani. Askese yang dijalankan secara setia akan membawa seorang rahib kepada apatheia, yakni keadaan kedamaian yang utuh, di mana seseorang dibebaskan dari segala nafsu dan egoisme. Jika seorang rahib mencapai keadaan 
ini, ia dimampukan untuk mengkontemplasikan ciptaan dan Sang Pencipta dengan pikiran dan pemahaman yang jernih. Kontemplasi mengenai alam ciptaan berjalan secara bertahap dan memuncak pada pemahaman akan misteri Trinitas. Praktike ini adalah hal yang mendasar dalam kemampuan berkontemplasi. Oleh karenanya Evagrius memberi perhatian khusus pada logismoi dan cara-cara pengelolaannya.

Dalam rangka Praktike (selanjutnya: Pr), Evagrius menyusun ajaran mengenai delapan pikiran buruk (On the Eight Thoughts $[E T]^{15}$ ) untuk mereka yang berada di tahap awal hidup sebagai rahib; mereka yang masih berjuang ambil jarak terhadap kehidupan duniawi dan masuk ke dalam gaya hidup pertapa. ${ }^{16}$ Tradisi "mundur dari kehidupan duniawi dan menjauhinya" (anachoresis) saat itu yang menjadi cikal bakal kehidupan membiara seperti yang kita kenal sekarang, bertujuan menghantar rahib mencapai kesempurnaan rohani. Dalam upaya menolak segala kenikmatan duniawi, seorang rahib harus berhadapan dengan delapan logismoi sebagai berikut: kerakusan (gluttony, gastrimargia), percabulan (fornication, porneia), ketamakan (avarice, filargyria), kesedihan (sadness, lupe), kemurkaan (anger, thymos/orge), kejemuan/ kelambanan (sloth, accedia), gila hormat/ cari popularitas (vainglory, kenodoxia), dan kesombongan (pride, hyperephania). ${ }^{17}$ Urutan tersebut mengacu pada dinamika hidup seorang rahib: ketika memulai matiraga, ia akan bergulat mengatasi godaan-godaan yang muncul dari kebutuhan dasar biologis (makan, minum, intimitas seksual) dan merambat ke kebutuhan akan materi, dan seterusnya, hingga berpuncak pada kebutuhan akan pengakuan diri.

Dalam On Thoughts (selanjutnya [OT]; Lat. De diversis malignis cogitationibus), Evagrius melihat ketiga serangkai pikiran jahat pertama: kerakusan, ketamakan, dan kesombongan, sebagai penyerang utama yang menghadang seorang rahib dalam upaya matiraga. Mereka bagaikan panglima-panglima pasukan setan yang berusaha menghambat rahib dalam peperangan menaklukkan diri sendiri untuk mencapai kemajuan hidup rohani. Jika seorang rahib jatuh pada salah satu godaan pikiran jahat ini, ia akan dibawa ke kelima pikiran yang lain (OT 1). Karena tiga serangkai pikiran jahat ini menyerang kelemahan manusiawi yang paling mendasar, dan karena kejahatan-kejahatan lainnya berasal dari mereka ini, maka Evagrius menafsirkan ketiga godaan setan dalam kisah percobaan Yesus di padang gurun (Luk 4:1-13) sebagai serangan ketiga pikiran jahat ini. Ketika membujuk Yesus mengubah batu menjadi roti, setan menggunakan kerakusan untuk mengarahkan Yesus jatuh ke dalam dosa. Selanjutnya, setan menggunakan ketamakan ketika ia menawarkan kepada Yesus segala kekuasaan duniawi. Dengan godaan terakhir untuk menjatuhkan diri dari bubungan Bait Allah, setan berusaha memprovokasi pikiran akan kemasyuran. Seorang rahib yang ingin mencapai kemajuan dalam hidup monastik harus berhasil menghadapi godaan yang juga dialami oleh Yesus. Lantas, bagaimana Evagrius memahami logismos ketamakan ini?

Untuk menjelaskan ketamakan, Evagrius menggunakan metafora. Sejalan dengan tradisi biblis, ia melihat ketamakan sebagai akar segala kejahatan (OT 3.1). Ketamakan memberi asupan makanan kepada ranting-ranting keinginan yang menuntut pemuasan. Jika satu ranting dipotong, ia nantinya akan tumbuh lagi. Seorang rahib yang tamak suka mengumpulkan banyak barang, ia seperti kapal yang kelebihan muatan. Di atas gelombang lautan, tiap saat ia bisa oleng dan tenggelam (OT 3.3). Sedangkan rahib yang telah menguasai pikiran akan macam-macam keinginan hanya memiliki barang seturut kebutuhannya. Ia bagaikan penjelajah yang tangkas-ringkas dan mampu menempuh perjalanan jauh. Ia bagaikan elang yang terbang tinggi dan sesekali menukik turun manakala ia butuh makan (OT 3.4-5). Evagrius pertama-tama memahami ketamakan sebagai kelekatan terhadap kepemilikan, namun juga melihatnya sebagai presentasi segala ikatan dengan realitas material. Sebagai anjuran praktis untuk mengatasi logismos ketamakan, Evagrius mendorong para rahib untuk melakukan tindakan amal $(\operatorname{Pr} 18) \cdot{ }^{18}$ Keutamaan amal kasih, khususnya kepada orang miskin, merupakan lawan dari ketamakan. ${ }^{19}$

Menurut pengamatan Evagrius, roh jahat ketamakan memiliki banyak akal untuk mengelabuhi manusia (OT 21). Bahkan keutamaan amal kasih sebagai senjata utama untuk memerangi ketamakan, bisa dimanipulasi oleh roh jahat ketamakan. Evagrius memberi contoh demikian: dalam beramal, motivasi seorang rahib bisa dibelokkan oleh roh jahat yang berpura-pura menjadi pemerhati orang miskin. Ia lantas mendorong rahib untuk lebih banyak membuat amal dan karya sosial, mengumpulkan sumbangan dari orang-orang kaya. Tentu 
saja tindakan macam ini mengundang pujian. Namun roh jahat ketamakan pelan-pelan mengarahkan rahib kepada logismoi gila hormat dan kesombongan. Karena itu Evagrius melihat kaitan erat antara ketamakan, besar mulut dan kesombongan (OT 21).

Dalam ajaran tradisional mengenai tujuh dosa pokok yang berkembang kemudian, logismoi dalam skema Evagrius disebut menjadi dosa pokok; kesedihan tidak termasuk dalam ajaran ini. Sementara yang dimaksud Evagrius dengan logismoi bukanlah dosa pokok tersebut melainkan godaan-godaan yang mengarahkan seseorang ke dosa pokok tertentu. ${ }^{20}$ Kerakusan bukanlah dorongan untuk makan sebanyak mungkin, melainkan cobaan untuk berhenti melakukan praktek askese karena alasan kesehatan. Dalam Praktikos, panduan hidup askesis yang memuat definisi mengenai tiap logismos dan strategi untuk menghadapinya, Evagrius misalnya menulis: "Kerakusan memberi saran kepada rahib untuk segera menghentikan mati raganya. Ia memberi gambaran kepada rahib mengenai kondisi perut, hati dan limpa, penyakit kembung ... Kadang ia mengingatkan rahib pada rekanrekannya yang telah menjadi korban penyakit macam itu ..." ( $\operatorname{Pr} 7)$. Jadi logismoi menunjuk kepada kecenderungan atau arah tertentu pikiranpikiran negatif. Jika pikiran-pikiran ini diikuti, orang akan dituntun ke arah dosa.

\subsection{Yohanes Kassianus}

Kassianus menyerap konsep delapan logismoi dari ajaran Evagrius ketika ia hidup di antara para rahib di Mesir, ${ }^{21}$ namun secara spesifik menyebutnya sebagai vitia. ${ }^{22}$ Pada tahun 399 Kassianus meninggalkan padang gurun Mesir. Beberapa tahun setelahnya ia menetap di Marseilles, di mana ia mendirikan komunitas para rahib yang mengorganisir kehidupan bersama (senobit). Dalam Institutes (Lat. De institutis coenibiorum et de octo principalibus vitiis) ia menyusun peraturan hidup membiara dan di dalamnya juga menulis ajaran mengenai delapan watak buruk. Dalam tradisi eremit lazim dibicarakan mengenai tema godaan setan yang berusaha membelokkan para rahib ke dalam dosa.

Dalam konsep mengenai delapan watak buruk, Kassianus membaginya menjadi dua kelompok: natural atau yang secara alami termasuk dalam instink manusia, dan unnatural atau yang tidak termasuk di dalamnya (Conf $\mathrm{V}$, III). Ketamakan termasuk dalam kelompok yang kedua. Ia tidak berasal dari kodrat alami manusia seperti halnya kerakusan dan percabulan, melainkan diprovokasi oleh realitas di luar tubuh manusia. Maka menurut Kassianus, ketamakan lebih mudah ditangani dibandingkan dengan kedua watak buruk tadi. Setiap saat seorang rahib berhadapan dengan realitas kebertubuhan berupa rasa lapar atau dorongan seksual sehingga logismos kerakusan atau percabulan selalu membayangi. Kendati lebih mudah dihindari, ketamakan lebih sulit ditangani jika seorang rahib membiarkan ketamakan tumbuh dan bercokol pada dirinya karena ketamakan akan memicu pikiran dan tindakan jahat lainnya, sedikit demi sedikit (Inst VII, 5-7). Dari ketamakan, muncul kejahatan-kejahatan berikut: pembunuhan, pertengkaran, ajaran sesat/penipuan, pencurian, kesaksian dusta, penghujatan, makan terlalu banyak, kemabukan, fitnah, kegilaan, kebohongan, sumpah palsu, gosip murahan, lawakan, kegelisahan, kegaduhan, kedongkolan (Conf V). Senada dengan pemahaman Evagrius dan pandangan biblis, ketamakan atau cupiditas (Lat.) adalah akar segala kejahatan. Pada kedelapan watak buruk ini, Kassianus lantas membedakan empat kelompok seturut cara beroperasinya: 1) watak yang tidak bisa terbentuk tanpa tindakan fisik (kerakusan, percabulan); 2) watak yang bisa terbentuk tanpa tindakan fisik (kesombongan, besar mulut), 3) watak yang terbentuk karena impuls eksternal (ketamakan, kemarahan); 4) watak yang terbentuk karena diprovokasi oleh sesuatu di dalam diri manusia (kemalasan/ keengganan, kesedihan). Untuk kelompok ketiga, Kassianus tampaknya mengacu pada obyek material. Uang, misalnya, bisa menjadi impuls eksternal bagi ketamakan.

Dalam Institutes, Kassianus menjelaskan tiga hakekat ketamakan dengan mengambil contoh dari kisah-kisah biblis (bdk. Inst VII, 14; Conf V, XI, 5). Pertama, ketamakan menghasut rahib untuk menginginkan apa yang tidak ia miliki. Hasrat memiliki ini mendorong kebohongan seperti kisah Gehazi, pelayan Nabi Elisa (2Raj 5:20-27). Kedua, ketamakan mendorong rahib untuk mendapatkan kembali apa yang telah ia sumbangkan kepada orang lain, sebelum ia menjalani hidup sebagai pertapa, dengan berbagai cara, termasuk mengkhianati sahabatnya seperti Yudas Iskariot (Mat 27:5). Ketiga, ketamakan memotivasi rahib untuk mempertahankan kepe- 
milikannya. Ia akan memicu ketidakjujuran dan mengkhianati kepercayaan komunitas, seperti halnya kasus Ananias dan Safira (Kis 5:1-11).

Kassianus lantas menawarkan solusi mengatasi ketamakan, yakni dengan sikap kemiskinan, hidup seperti jemaat perdana (bdk. Inst VII, 17). Konteks solusi ini perlu dipahami: pengaturan sikap terhadap kepemilikan pribadi dalam tradisi senobit lebih ketat daripada dalam tradisi eremit. Dalam tradisi senobit, komunitas memungkinkan penyelenggaraan kehidupan bersama, sedangkan dalam tradisi eremit, tiap rahib mau tidak mau harus memiliki barang, dalam standar minimal. Menjual barang hasil kerja tangan tak lagi menjadi urusan pribadi, tapi urusan komunitas. Tentu saja tetap ada bahaya mengumpulkan harta sebanyak-banyaknya demi kekayaan komunitas. Ketika roh jahat ketamakan merasuki pikiran seorang rahib yang malas, ia akan merangsang kekuatiran mengenai krisis ekonomi yang sewaktu-waktu bisa melanda komunitas biara. Jika kesulitan ini terjadi, ia akan terkena dampaknya. Makin lama bercokol pikiran bahwa kekayaan/keuangan biara tidak cukup, kekuatira semakin menjadi-jadi. Lalu ia mulai melakukan karya pribadi demi pemasukan pribadi tanpa sepengetahuan pemimpin biara. Makin banyak mengumpulkan, orang semakin kuatir (bdk. Inst VII, 7).

\subsection{Gregorius Agung}

Melalui Kassianus, spiritualitas Yunani (Timur) mengalami asimilasi di lingkup dunia Latin (Barat). Namun tradisi rohani para bapa padang pasir masih terakumulasi di dalam tembok biara. Skema delapan watak buruk pada dasarnya menjadi pedoman moral para rahib, mereka yang mengejar perkembangan dan kesempurnaan hidup rohani. Di tangan Gregorius Agung, ajaran mengenai delapan watak buruk ini mengalami perkembangan, ketika ia disesuaikan dengan kehidupan awam pada umumnya. Kassianus, seperti halnya Evagrius, dalam lingkup tradisi eremit dan senobit, memandang kurang positf hal-hal duniawi. Sementara Gregorius sebagai paus mendorong orang Kristen ambil bagian dalam tanggungjawab publik, namun perlu menyeimbangkan dengan kehidupan rohani pribadi. ${ }^{23}$ Karena orientasi Gregorius bukan kehidupan membiara, maka urutan skema tradisional watak-watak buruk mengalami penyesuaian. Skema delapan logis- moi Evagrius dan vitia Kassianus berawal pada kerakusan dan percabulan, dua watak buruk yang berkaitan erat dengan kebutuhan jasmani. Ini mencerminkan tahapan upaya para rahib untuk mencapai kesempurnaan rohani, yang diawali dengan pergulatan melawan godaan-godaan badaniah. Sementara Gregorius menyusun urutan demikian: kesombongan, kedengkian, kemarahan, kesedihan, ketamakan, kerakusan, dan percabulan. ${ }^{24}$ Berkebalikan dengan konsep tradisi askese, Gregorius memulai dari vitia spiritualia, yakni kelima watak buruk pertama yang berkaitan dengan kebutuhan rohaniah manusia, dan berakhir pada vitia carnalia, yakni kerakusan dan percabulan yang berkaitan dengan kebutuhan jasmaniah. Dari modifikasi urutan ini, patrolog dan spesialis sejarah abad pertengahan Richard Newhauser dari Universitas Arizona menyimpulkan bahwa Gregorius tidak menekankan upaya pembebasan individual dari aneka macam godaan jasmaniah. ${ }^{25}$ Ia melihat bahwa individualisme berada di balik semua dosa. Untuk mengatasi individualisme diperlukan internalisasi disposisi kerendahan hati dan ketaaatan di hadapan Allah. Para pembaca Gregorius di luar tembok biara tentunya lebih mudah menerima gagasan mengenai ketaatan baik di hadapan otoritas duniawi (negara) maupun ilahi (Gereja) di balik ajaran tujuh vitia ini. Ide mengenai upaya mengatasi dorongandorongan jasmani tentunya tidak mudah diasimilasikan ke dalam kehidupan awam seharihari. Jadi ajaran tradisional delapan watak buruk mengalami modifikasi karena perubahan fungsi; tidak lagi sebagai tuntunan perkembangan moral para rahib, namun orang Kristen kebanyakan, serta melayani kepentingan katekese. Tujuh vitia lambat laun dipandang sebagai tujuh dosa pokok, berlawanan dengan tujuh anugerah Roh Kudus. ${ }^{26}$

Seperti halnya ajaran vitia principalia sebelumnya, Gregorius menyusun daftar serangkaian kejahatan yang menurun dari ketamakan, yakni pengkhianatan terhadap kepercayaan orang lain (treachery), penipuan (fraud), kecurangan (deceit), sumpah palsu (perjury), kegelisahan/ ketidaksabaran (restlessness), kekerasan (violence), keras hati (hardness of heart against compassion). ${ }^{27}$ Dibandingkan dengan versi-versi pendahulunya, daftar turunan ketamakan menurut versi Gregorius mengangkat nuansa baru dengan menempatkan kekerasan sebagai tindakan dan sikap. Namun selain kekerasan, daftar turunan ketamakan ala Gregorius lebih mengarah pada 
keadaan psikologis dan kurang menunjuk pada tindakan aktual sebagaimana daftar Evagrius atau Kassianus.

Newhauser mencatat bahwa di abad pertengahan ketamakan dan kesombongan saling bersaing mendapatkan supremasi dalam jajaran watak-watak buruk atau dosa-dosa pokok. Keduanya mempunyai dasar biblis. Supremasi masing-masing mendapatkan dukungan dari konteks sosiokultural suatu era perabadan. ${ }^{28}$ Kesombongan dipandang sebagai akar segala kejahatan, ketika masyarakat abad pertengahan menjunjung tinggi keteraturan dan stabilitas. Individualisme, pemberontakan terhadap tatanan sekular maupun ilahi dianggap sebagai pelanggaran berat. Sementara hegemoni ketamakan dalam jajaran dosa pokok berlangsung manakala dalam masyarakat golongan pedagang dan borjuis melampaui fungsi sosial dan ekonomis yang sebelumnya dimiliki oleh golongan aristokrat.

\section{KETAMAKAN DARI PERSPEKTIF SOSIOLOGIS}

Pembicaraan mengenai ketujuh dosa (pokok) tidak harus selalu terjadi di ruang lingkup teologis. Stanford M. Lyman ( - 2003), seorang sosiolog Amerika, pada tahun 1978 menerbitkan sebuah buku berjudul The Seven Deadly Sins: Society and Evil. Di situ Lyman membicarakan tujuh serangkai dosa pokok dengan mencoba memberikan definisi masing-masing dosa, lantas berkelana di belantara sejarah peradaban manusia untuk melihat perubahan definisinya, terutama manifestasinya dalam teologi atau karya sastra. Tiap bab - satu bab untuk satu dosa - umumnya diakhiri Lyman dengan menggelar diskusi mengenai contoh-contoh dosa yang bersangkutan dalam masyarakat sekular. Kendati Lyman mengangkat tujuh serangkai dosa pokok yang menjadi baku sejak Gregorius Agung, ia tidak memberi definisi yang jelas mengenai dosa. Lyman menyebut tujuh serangkai sebagai dosa mematikan (deadly sin). Dalam lingkup teologi, sebutan "mematikan" menandai kematian rohani (spiritual death), artinya hilangnya relasi antara Allah dan manusia secara definitif. Sementara itu dosa dalam katalog Gregorius disebut capital/ cardinal karena mereka menjadi kepala atau asal muasal dosa-dosa yang lain, namun tidak otomatis menghantar manusia kepada putusnya relasi dengan Allah secara definitif.
Absennya definisi teologis ini di satu sisi bisa dimaklumi mengingat interese Lyman terletak pada pengamatan atas fenomena kejahatan dalam realitas sosial. Definisi teologis dosa oleh karenanya sedikit diabaikan Lyman. Di sisi lain, terdapat semacam "lompatan konteks". Ajaran mengenai ketujuh serangkai dosa pokok lahir dan berkembang dalam latar belakang masyarakat Kristen (yang berakar pada pemikiran helenis, yudaistik). Sementara itu, Lyman mengaplikasikan definisi ketujuh dosa tersebut ke dalam persoalan global, ke dalam aneka kultur dan peradaban. Kendati ini menjadi kritik terhadap metodologi Lyman, intensi Lyman untuk melihat kejahatan sebagai fenomena sosial, dan dengan demikian membuat kontekstualisasi sosiokultural terhadap ajaran tujuh dosa pokok, perlu mendapat apresiasi. Bahwa tema kejahatan (evil) sering diabaikan dalam diskursus sosiologi atau filsafat moral menjadi alasan Lyman menulis bukunya. "Evil seems to be great, too impersonal, and to absurd to be a serious topic for sociological concern. Its very omnipresence, grossness, and grotesqueries defy and transcend the sociological imagination" (hlm. 1).

Mengangkat karya Lyman dalam kerangka teologi moral, juga menimbulkan "lompatan konteks", sebab pergumulan intelektual intensif mengenai tujuh serangkai dosa pokok di tangan Thomas Aquinas (dalam Summa Theologia, Ia-2ae, 71-89) misalnya, dilewati begitu saja. Istilah "lompatan konteks" di sini juga memuat perbedaan cara pandang manusia pada zaman Gereja Purba sampai periode Para Bapa Gereja dan manusia modern mengenai dunia. Misalnya, jika dulu aktivitas duniawi (misalnya perdagangan, lantaran motivasi mencari keuntungan sebanyak-banyaknya) pernah dinilai negatif, pandangan itu berubah seiring makin kompleksnya sistem perekonomian dunia. Namun demikian, upaya Lyman dalam merekonstruksi definisi ketujuh dosa dalam sejarah peradaban, bisa menawarkan jembatan bagi orang masa kini untuk memahami kesatuan gagasan awal mengenai ketujuh dosa itu.

Khusus mengenai dosa ketamakan, Lyman menyodorkan narasi mengenai pudarnya status "jahat" yang melekat pada ketamakan. Telah disinggung di atas, bahwa ketamakan dalam jajaran tujuh serangkai dosa di era Gereja Purba hingga Abad Pertengahan mengalami pergeseran posisi. Ia pernah menempati posisi kunci - menjadi akar bagi keenam dosa yang 
lain - dalam suatu tatanan sosial (yang tentu saja Eropa-kristiani), di mana kalangan borjuis dan pedagang memainkan peran penting dalam tatanan sosial, bahkan lebih penting daripada bangsawan atau klerus. Dalam narasi pudarnya status jahat ketamakan, Lyman menelisik perkembangan sistem niaga dunia yang mengubah pandangan dan sikap orang terhadap uang, alat pembayaran yang mulai menjadi baku. "Economics justifies avarice by lifting the stigma of evil from ist practice" (hlm. 239). Sistem tukar menukar barang lantas menjadi pilar sosial penting dalam masyarakat modern. Hasil bumi dan hasil pekerjaan tangan menghasilkan uang, yakni selembar kertas atau sekeping logam yang nilainya jauh lebih tinggi dari harga materialnya sendiri. Uang lantas menjadi obyek keserakahan manusia. Di sisi lain, uang diakui fungsinya dalam perkembangan suatu peradaban. Dorongan untuk mencari keuntungan lebih banyak menggerakkan dinamika perekonomian, yang pada gilirannya mendukung kemajuan suatu peradaban. Ilmu pengetahuan dan teknologi dimungkinkan berkembang karena ada dana.

Ketika sistem perekonomian modern semakin kompleks, ketamakan juga mengalami perubahan karakter. Lyman menyebutnya sebagai patterned and collective institutionalization of greed (hlm. 249). Sistem perekonomian tak lagi mencakup transaksi jual beli atau tukar menukar barang antar individu atau kelompok-kelompok kecil, melainkan melibatkan lembaga-lembaga transnasional yang beroperasi lintas benua. Karena pelaku perekonomian menjadi semakin anonim, ketamakan semakin memiliki karakter kolektif. Ketamakan kini mengambil wujud lembaga-lembaga ekonomi dan perdagangan yang bergerak dengan modal amat besar dan mentarget keuntungan yang amat besar pula. Bahkan mereka punya pengaruh politis seperti yang dipunyai rezim penguasa suatu negara; mereka bisa menentukan nasib banyak orang. Di sini tampak bahwa analisis Lyman atas kejahatan menekankan efek atas transformasi korporasikorporasi menjadi pelaku-pelaku kejahatan yang tanpa perasaan (soulless evildoers). Bukti bahwa lembaga-lembaga atau sistem sosial telah berubah wujud menjadi pelaku kejahatan adalah distribusi kesejahteraan yang tidak merasa, jurang yang lebar antara orang miskin dan kaya. Keserakahan telah menyebabkan ketidakadilan, memprovokasi konflik dengan kekerasan, dan menebar kesengsaraan.

\section{PENUTUP}

Kiranya tidak berlebihan jika celeng dalam lukisan Djoko Pekik ditafsirkan sebagai simbolisasi rezim Orde Baru yang memang berhasil melembagakan ketamakan. Rezim ini dikenang melahirkan pejabat-pejabat (beserta birokrasi yang korup dan tidak efisien) dan pengusaha-pengusaha maha kaya, namun problematis. ${ }^{29}$ Penguasa politik dan ekonomi bahumembahu mengeruk dan mengumpulkan kekayaan. Kerjasama antara rezim korup dan pelaku ekonomi yang eksploitatif terhadap manusia dan alam ini menciptakan sistem yang menguntungkan segelintir manusia saja dan melebarkan jurang antara orang kaya dan miskin. Namun ketika riwayat rezim tersebut berakhir, apakah ketidakadilan dan kesengsaraan rakyat miskin juga berakhir? Dalam bahasa Sindhunata: "Celeng sudah tertangkap, tapi mengapa situasi tidak menjadi lebih baik?"

Di awal telah disinggung pergeseran penafsiran atas visualisasi celeng. "Celeng yang tertangkap rakyat sesungguhnya bukanlah binatang celeng, melainkan celeng jadi-jadian," tulis Sindhunata. Celeng tidak hanya diartikan sebagai simbol rezim penguasa yang rakus, namun juga sebagai kekuasaan jahat yang bekerjasama dengan nafsu keserakahan manusia. Simbol celeng dan pemaknaan di sekitarnya merupakan sarana untuk membahasakan kesadaran moral, di mana orang melihat ketamakan sebagai ancaman bagi keberlangsungan hidup bersama.Dengan penggambaran ini, kita dibawa kembali kepada sejarah tradisi kristiani awal mengenai vitia principalia, di mana keserakahan sudah dipandang sebagai „musuh berat“ manusia untuk mencapai keselamatan. Ajaran mengenai daftar pikiran jahat (Evagrius) berkembang dalam konteks pengalaman para Bapa padang gurun yang ingin mengikuti jejak Yesus, dengan menepi ke padang gurun untuk bertemu face to face dengan iblis. Dalam laku askese dan hidup menyendiri, para eremit berhadapan dan memerangi dorongandorongan nafsu yang muncul baik dari kebutuhan jasmaniah maupun rohaniah. Mereka memandang roh jahat seakan-akan sebagai figur riil yang mempunyai karakteristik tertentu. Dan karakter menonjol dari iblis adalah kemampuannya mengelabuhi dan memperdaya manusia dengan berbagai cara, hingga manusia terpisah dari relasi dengan Sang Pencipta. Menurut Evagrius, iblis tidak bisa mengetahui hati manusia - hanya 
Allah yang bisa melihat isi hati manusia. Namun demikian, iblis mengamati tingkah laku manusia, memperhatikan kecenderungan-kecenderungan manusia, dan menyerang persis pada titik lemah tersebut (bdk. Lk 4:13).

Untuk memerangi iblis, Evagrius telah menawarkan metode, yakni memberikan nama pada si roh jahat dan melihat mekanisme cara kerjanya. ${ }^{30}$ Kemampuan memberi nama menunjukkan bahwa orang mempunyai pendirian tertentu, di mana ia bisa memberi penilaian pada daya-daya yang mempengaruhi cara berpikir dan bertindaknya. Mengangkat celeng sebagai simbolisasi ketamakan kiranya menjadi wujud dari usaha memberi nama terhadap kecenderungan-kecenderungan negatif pada manusia. Dalam tradisi monastik ada upaya untuk menginventarisir kejahatan-kejahatan yang muncul dari suatu watak buruk (vices). Ini adalah cara untuk memahami, bagaimana pikiran-pikiran atau roh jahat mempengaruhi cara berpikir dan bertindak manusia. Menarik simbolisasi celeng ke arah fenomena kultural ilmu hitam celeng gontheng atau babi ngepet paralel dengan usaha menginventarisir karakteristik ketamakan dalam konteks situasi masyarakat tertentu. Upaya ini masih harus dilanjutkan dengan mencari caracara penanggulangannya.

Setelah lukisan Celeng telu Pekik dan refleksi Sindhunata mengenai misteri kekuasaan jahat "celeng jadi-jadian", para uskup dan umat Katolik membahasakan situasi sama dalam Nota Pastoral (NP) 2004. Di situ disimpulkan bahwa ketidakadaban publik sebagai habitus lama telah merusak sendi-sendi kehidupan berbangsa dan bernegara. Salah satu contoh habitus lama itu adalah korupsi - entah dilakukan dalam skala besar atau kecil. Jika kita sekarang membuat daftar turunan kejahatan dari keserakahan, korupsi tentu termasuk di dalamnya. Korupsi adalah salah satu vice turunan dari capital vice ketamakan. Mentalitas dan perilaku koruptif ini adalah wujud dari nafsu keserakahan yang dialegorikan sebagai celeng. Dengan mengangkat ketamakan sebagai persoalan moral di Indonesia, ada tawaran untuk mendekati persoalan habitus lama korupsi pertama-tama dengan menganalisis faktor-faktor internal pada kepribadian dan perilaku (sekelompok) manusia, karena "the inner condition of the heart is what gives rise to greed 's outer manifestation." ${ }^{31}$ Watak buruk pada dasarnya adalah kebiasaan jiwa.
Namun analisis ini tidak boleh berhenti pada abstraksi terhadap individu saja. Dengan cara pandang sosiologis, Lyman mengaktualisasikan ajaran tradisional tujuh dosa pokok untuk menganalisis fenomena kejahatan dalam aneka bentuknya. Definisi ketamakan sebagai hasrat yang begitu besar untuk memiliki obyek material maupun non-material semakin banyak mendapatkan aktualisasinya dari runutan perkembangan aktivitas ekonomi dalam sejarah peradaban manusia. Di sini perlu dicatat point penting pengamatan Lyman: keserakahan lambat laun dibebaskan dari penilaian moral. Jika kita mengamati rasionalitas ekonomi yang dibimbing oleh mekanisme pasar yang impersonal dan sistem ekonomi-politik yang eksploitatif, kita mengamini ungkapan radix malorum est cupiditas. Maka analisis Lyman di atas mendorong dimaksukkannya kembali keserakahan, cinta akan uang, atau obsesi akan keuntungan berlebih ke dalam penilaian moral kembali, kendati itu sudah diterima sebagai sesuatu yang lazim dalam logika ekonomi, bahkan politik.

Mengangkat simbolisasi celeng adalah upaya untuk mengangkat persoalan ketamakan sebagai persoalan moral yang serius. Ia menyentuh persoalan etika politik dan berurusan dengan struktur-struktur sosial, di mana ketamakan dilembagakan. Pada point ini, kita diingatkan pada pengelompokan watak-watak buruk versi Kassianus, bahwa ketamakan tidaklah muncul dalam diri manusia seperti halnya lapar dan haus - keduanya timbul dari metabolisme biologis di dalam tubuh. Ketamakan selalu mengandaikan adanya kepemilikan orang lain, baik material (harta benda, uang, sawah, ladang, ternak) maupun non-material (jabatan, status sosial, jaminan sosial). Oleh karena itu, ketamakan adalah social vice. Istilah habitus dalam NP mengacu pada perilaku kolektif dalam konteks budaya dan sejarah Indonesia (keadaban publik sebagai habitus baru bangsa). Di sini diperlukan kajian sosiopolitik dan sosiokultural mengenai perkembangan sistem perekonomian yang berlaku di Indonesia, khususnya selama periode Orde Baru. Faktor-faktor eksternal yang mempengaruhi perilaku dan disposisi moral dicermati dalam kajian tersebut.

\section{Dionisius Bismoko Mahamboro}

Studi Program Doktoral Teologi Moral Universitas Insbruck Austria: mahamboro@ gmail.com. 


\section{CATATAN AKHIR}

1 Bdk. T. Edi Nugraha, "Makna Trilogi Celeng Karya Seni Lukis Djoko Pekik", Dewa Ruci Vol 6 Nr 3 (2010) 441-449; N. Florida, "A Proliferation of Pigs: Specters of Monstrosity in Reformation Indonesia”, Public Culture, Vol 20 Nr 3 (2008) 497-530.

2 Sindhunata, Tak Enteni Keplokmu: Tanpa Bunga dan Telegram Duka, 35.

3 Bdk. Sindhunata, "Negeri Para Celeng", Kompas 31 Mei 2011, 5.

4 Sementara yang lain adalah: kesombongan, kedengkian, kemurkaan, percabulan, kerakusan, kelambanan, atau kejemuan (Lat. acedia). Bdk. Katekismus Gereja Katolik Nr. 1866.

5 Tampaknya si penanya adalah anak kedua dari dua bersaudara. Saudara sulungnya menolak berbagi warisan. Mengenai tradisi pembagian warisan yang melatarbelakangi perikop Lukas ini, lih. E. Bovon, Das Evangelium nach Lukas, EvanglischKatholischer Kommentar zum Neuen Testament (selanjutnya disingkat: EKK) III/2, 276-277.

6 Istilah vices (antonim dari virtues atau "keutamaankeutamaan"; berakar pada kata Latin vitium) diterjemahkan menjadi "kebiasaan-kebiasaan buruk" dalam KGK. Istilah tersebut pertama-tama menunjuk amoralitas pada karakter seseorang (bdk. Cambridge Advanced Learner's Dictionary, Cambridge University Press, Cambridge 2008, 1617). Namun ia juga digunakan secara lebih lazim untuk menunjuk kebiasaan atau tabiat buruk. Dalam tulisan ini digunakan istilah "watak buruk/ negatif" untuk menunjuk pengertian vices.

7 Diagnose Erich Fromm terhadap masyarakat modern menunjukkan bahwa kodrat materialisme manusia dalam modus to have lebih berkembang daripada modus to be. E. Fromm, Haben oder Sein: die seelischen Grundlagen einer neuen Gesellschaft (judul asli: To Have or To Be?).

8 Bdk. M. Hengel, "Eigentum und Reichtum in der frühen Kirche", dalam: C.-J. Thornton (ed.), Studien zum Urchristentum. Kleine Schriften VI, 372-374.

9 Bdk. F. Bovon, EKK III/3, 80, 95 (catatan kaki Bovon nr. 36).

10 Studi komprehensif mengenai metafora ini dalam perspektif etis, lih. B. S. Rosner, Greed as Idolatry. The Origin and Meaning of a Pauline Metaphor.

${ }_{11}$ Mengenai peran list of virtues and vices dalam pewartaan Paulus, lih. J. W. Thompson, Moral Formation according to Paul. The Context and Coherence of Pauline Ethics, 87-110.
12 Bdk. V. Mihoc, "The Final Admonition to Timothy (1Tim 6,3-21)" ,dalam: K. P. Donfried (ed.), 1 Timothy Reconsidered, 143-144.

13 Mengenai panorama perkembangan moralitas jemaat Kristen awal, lih. W. A. Meeks, The Origins of Christian Morality. The First Two Centuries; J. P. Wogaman, Christian Ethics. A Historical Introduction, 27-52

14 C. Stewart, "Evagrius Ponticus and the Eight Generic Logismoi" dalam: R. Newhauser (ed.), In the Garden of Evil. The Vices and Culture in the Middle Ages, 16.

15 Tulisan-tulisan Evagrius yang dikutip di sini dirujuk dari terjemahan Yunani ke dalam bahasa Inggris oleh R. E. Sinkewicz, Evagrius of Pontus. The Greek Ascetic Corpus.

16 Bdk. Sinkewicz, Evagrius of Pontus, 66-90.

17 Terjemahan untuk istilah-istilah dalam bahasa Inggris dan Yunani dalam tanda kurung mengikuti terjemahan yang digunakan dalam KGK $\mathrm{Nr}$. 1866. Para sejarawan terbuka pada kemungkinan bahwa skema delapan pikiran ini bukan kekhasan Evagrius karena ini sudah berkembang di lingkup tradisi monastik Mesir pada abad ke-4. Di sisi lain, mereka menegaskan kekhasan Evagrius yang tampak dalam urutan logismoi seperti di atas, di mana ketamakan berada pada urutan ketiga. Bdk. R. Newhauser, The Early History of Greed. The Sin of Avarice in Early Medieval Thought and Literature, 53-54.

18 Bdk. Praktikos 18 (ed. Sinkewicz, 101).

19 Untuk memahami deskripsi Evagrius mengenai godaan ketamakan (philargyria), kita perlu membayangkan konteks hidupnya saat itu. Sebagai rahib eremit, ia tinggal sendirian di sebuah sel/ pondok kecil dan menjalani sebagian waktunya dalam doa, meditasi Kitab Suci, dan bekerja. Satu kali seminggu, yakni pada hari Sabtu malam, mereka berkumpul untuk makan bersama. Di hari Minggu, mereka merayakan misa bersama. Para rahib menghidupi dirinya sendiri dari kerja tangan mereka, entah dengan membuat kerajinan atau bercocok tanam di kebun mereka yang kecil. Nasihat St. Paulus "Barangsiapa tidak bekerja, tidak boleh makan" (2 Tes 3:10) dimaknai secara literer. Hasil kerja mereka dijual di pasar dengan harga rendah. Uang penjualan itu lantas digunakan untuk membeli bahan makanan secukupnya dan sisanya disumbangkan kepada orang miskin. Dengan cara ini mereka melatih keseimbangan batin: di satu sisi berada pada posisi tergantung pada kebaikan orang lain yang mau menghargai 
hasil tangan mereka, namun di sisi lain berada pada posisi pelaku tindakan karitatif.

20 K. Corrigan, Evagrius and Gregory. Mind, Soul and Body in the 4th Century, 75.

21 Tulisan-tulisan Yohanes Kassianus yang dikutip di sini dirujuk dari terjemahan Latin ke dalam bahasa Inggris oleh B. Ramsey (John Cassian: The Conferences) dan J. Bertram (The Monastic Institutes). The Conference ditulis di padang gurun Mesir, merupakan refleksi dan ajaran para bapa padang gurun yang dikumpulkan Kassianus untuk para muridnya, yakni para rahib eremit di padang gurun Mesir. Tema mengenai eight principal vices berada di bagian pertama The Conferences (konferensi ke-5). Bagian pertama ini bisa disebut sebagai pedoman hidup eremit, sedangkan Institutes disebut sebagai pedoman hidup senobit. Bdk. Ramsey, John Cassian, 28.

22 Mengenai perkembangan penyebutan logismoi (Evagrius), vitia (Kassianus), hingga dosa (Gregorius Agung), lih. R. Newhauser, The Treatise on Vices and Virtues in Latin and the Vernacular, 180-202.

23 Mengenai biografi Gregorius Agung dan pemikirannya, lih. G.R. Evans, The Thought of Gregory the Great; E. Schockenhoff, "Gregor der Große", dalam: K. Hilpert (ed.), Christliche Ethik im Porträt, 151-169.

24 Bdk. Moralia XXXI, 87. Konsep Gregorius mengenai tujuh principalia vitia hanya muncul sekali dalam seluruh tulisannya, yakni di Moralia in Job XXXI.Terjemahan ke dalam bahasa Inggris oleh J. H. Parker/ F. and J. Rivington, Morals on the Book of Job by S. Gregory the Great, 2nd part of Vol. III Book XXX-XXXV, Oxford, 1844. Secara digital dapat diaksespada: http://www.lectionarycentral.com/GregoryMoraliaIndex.html.

25 Bdk. Newhauser, The History, 102-103; idem, The Treatise, 188.

26 "For, because $\mathrm{He}$ grieved that we were held captive by these seven sins of pride, therefore our Redeemer came to the spiritual battle of our liberation, full of the spirit of sevenfold grace." Moralia XXXI, 87. Bdk. Newhauser, The Treatise, 189.

27 Moralia XXXI, 88.

28 Bdk. Newhauser, Treatise, 198 dst.

29 Sejarah munculnya kelompok konglomerat dan relasinya dengan rezim, lih. A. Ufen, Herrschaftsfiguration und Demokratisierung in Indonesien (1965-2000), 34-80, 149-187.

30 A. Grün, Der Umgang mit dem Bösen, 63-64.
31 R. K. DeYoung, Glittering Vices. A New Look at the Seven Deadly Sins and their Remedies, 100.

\section{DAFTAR PUSTAKA}

Bertram, J., 1999. The Monastic Institutes, The Saint Austin Press, London.

Bovon, E., 2008. Das Evangelium nach Lukas, Evanglisch-Katholischer Kommentar zum Neuen Testament III/2, Neukirchener Verlag, Neukirchen-Vluyn.

Corrigan, K.,2009. Evagrius and Gregory. Mind, Soul and Body in the 4th Century, Ashgate, Farnham.

DeYoung, R., 2009. Glittering Vices. A New Look at the Seven Deadly Sins and their Remedies, Brazos Press, Grand Rapids.

Donfried, K. (ed.), 2008. 1 Timothy Reconsidered, Peeters, Herent.

Edi Nugraha, T., 2010. "Makna Trilogi Celeng Karya Seni Lukis Djoko Pekik", Dewa Ruci Vol 6 Nr 3 (2010) 441-449.

Evans, G., 1986. The Thought of Gregory the Great, Cambridge University Press, Cambridge.

Florida, N., 2008. "A Proliferation of Pigs: Specters of Monstrosity in Reformation Indonesia“", Public Culture, Vol 20 Nr 3 (2008) 497-530.

Fromm, E., 1977. Haben oder Sein: die seelischen Grundlagen einer neuen Gesellschaft (judul asli: To Have or To $B e$ ?), Stuttgart.

Grün, A., 2011. Der Umgang mit dem Bösen, VierTürme-Verlag, Münsterschwarzach.

Hilpert, K. (ed.), 2012. Christliche Ethik im Porträt, Herder, Freiburg i. Br.

Lyman, S., 1989. The Seven Deadly Sins. Society and Evil, General Hall, Oxford.

Meeks, W., 1993. The Origins of Christian Morality. The First Two Centuries, Yale University Press, London.

Newhauser, R.,1993. The Treatise on Vices and Virtues in Latin and the Vernacular, Brepols.

Newhauser, R.,2000. The Early History of Greed. The Sin of Avarice in Early Medieval Thought and Literature, Cambridge University Press, Cambridge. 
Newhauser, R. (ed.), 2005. In the Garden of Evil. The Vices and Culture in the Middle Ages, PIMS, Ontario.

Parker, J.,1844. Morals on the Book of Job by S. Gregory the Great, 2nd part of Vol. III Book XXX-XXXV, Oxford. Secara digital dapat diakses pada: http://www.lectionarycentral.com/ GregoryMoraliaIndex.html.

Ramsey, B., 1997. John Cassian: The Conferences, Paulist Press, New York.

Rosner, B., 2007. Greed as Idolatry. The Origin and Meaning of a Pauline Metaphor, Eerdmans, Grand Rapids.

Sinkewicz, R., 2003. Evagrius of Pontus. The Greek Ascetic Corpus, Oxford University Press, New York.

Thompson, J., 2011. Moral Formation according to Paul. The Context and Coherence of Pauline Ethics, Baker Academic, Grand Rapids.
Thornton, C.-J. (ed.), 2008. Studien zum Urchristentum. Kleine Schriften VI (edisi pertama: Stuttgart, Calwer Paperback, 1973), Mohr Siebeck, Tübingen.

Sindhunata, 1999. Tak Enteni Keplokmu: Tanpa Bunga dan Telegram Duka, Gramedia, Jakarta.

Sindhunata, 2011. "Negeri Para Celeng”, Kompas 31 Mei 2011, hlm. 5.

Ufen, A., 2002. Herrschaftsfiguration und Demokratisierung in Indonesien (19652000), Hamburg.

Wogaman, J., 2011. Christian Ethics. A Historical Introduction, WJK Press, Louisville. 